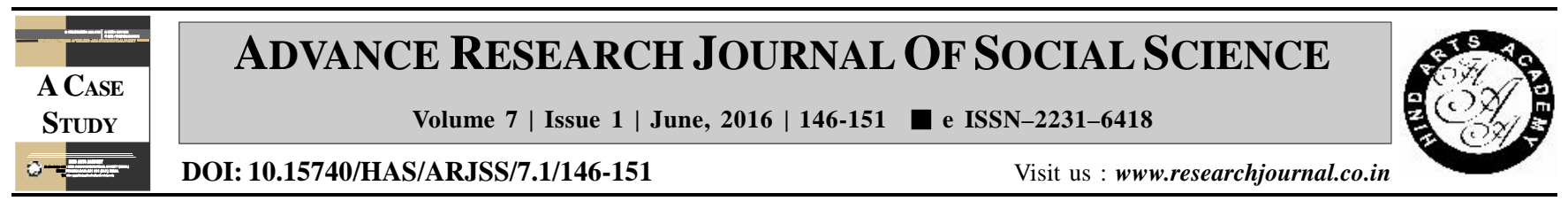

\title{
Sopana musicians of Kerala temples : Problems and prospects
}

\author{
S. Soumya
}

Department of History, N.S.S. College, Pandalam, PATHANAMTHITTA (KERALA) INDIA

(Email: soumyaplr1981@gmail.com)

\section{ARTICLE INFO :}

Received : 19.04 .2016

Accepted : 26.05.2016

\section{KEY WORDS :}

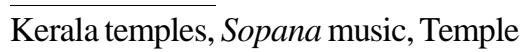
art, Ritual, Performing arts

\section{HOW TO CITE THIS ARTICLE :}

Soumya, S. (2016). Sopana musicians of Kerala temples : Problems and prospects. Adv. Res. J. Soc. Sci., 7 (1) : 146-151, DOI: 10.15740/HAS/ARJSS/7.1/146151.

\begin{abstract}
Studies dealing with ritualistic music and allied arts of Kerala are rare. Not much research has gone deep into this area which cut across the periphery and superficial layers and touch the real core. An analytical study on the virtually vanishing temple art of Kerala, the Sopana Music, is really significant in this context. Their existence is greatly threatened by the process of modernisation and commercialization of life in the contemporary age and the accompanying changes in social and economic structure. At one time, Sopana music system was associated with most of the rituals and the performing arts. Yet what one sadly realises now-a-days is the fact that Sopana music is still groping in darkness and is yet to be restored to its original spirit and charm. Owing to historical reasons, the recital of this music came to be neglected and virtually discarded in most of the areas except in some temples where it was preserved as a ritual. The reasons for its setback could be many- the practitioners inability to verbalise the content and substance of their art and their inhibition to violate the rigid, protective, orthodox rules and norms intended to preserve their sanctity. The foremost among the reasons being the fear of ominous consequences, if sacred practices were exposed outside the temple sanctum. It was apprehended, that putting the sacred oral traditions in writing, would defile the divinity and sanctity of the art forms, as it might distort the authentic expression of many typical sounds, their volume, cadence, intonations, signs, accents etc. There appears to be no consensus regarding the mode of preservation of this ritualistic art form.
\end{abstract}

